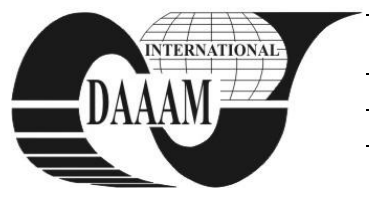

\title{
A LIFE-CYCLE ANALYSIS OF A NEW ROMANIAN AUTOMOTIVE MANUFACTURING BATTERY
}

\author{
GHENADI, A[drian] S[telian]; BIBIRE, L[uminita] \& TOPLICEANU, L[iliana]
}

\begin{abstract}
Rombat S.A. is the largest producer of lead-acid batteries in Romania and also an important source of environmental pollution. So, it is necessary to be able to calculate the quantity of waste created during the life cycle of the product, much fundamental information on manufacturing processes, materials and used energy. For this reason we proposed to solve these global problems using Life Cycle Assesment method, with a dedicated software program (SimaPro 7) to simulate a life cycle of car batteries, more precisely. This fact allows to understanding the concept of life cycle by creating a concrete example, quantify the potential environmental effects of the product, for effective characterization of life cycle stages

Key words: environmental impacts evaluation, lead-acid battery, life cycle assessment, Sima Pro 7 software
\end{abstract}

\section{INTRODUCTION}

According to official statistics, every year, in the world, more than 80 million lead-acid car batteries are produced.

These batteries have considerably energy consumption in production stage and they produce residues with environmental impact, including their recycling process. When these batteries are not recycled, they often end up in landfills, where the lead elements and acid eventually seeps from battery and contaminates the nearby soil. They don't pollute only the soil, but any nearby water source or groundwater.

Thus, when these lead-acid batteries reach at the end of their useful life, they constitute a danger for the people, animals and the environment, if they are destroyed improperly. However, some of these batteries can be recycled easily and managed to conserve resources and reduce their environmental impact.

In Romania, the largest manufacturer of automotive batteries is Rombat SA from Bistrita city. For 2011, Rombat has set a target of selling of 2.26 million automotive batteries. Approximately, 54\% of its production is exported from Bistrita in 24 countries, mainly on the French market, where Rombat holds $10 \%$ of market. Internally, Rombat occupy $65 \%$ of the total market and $54 \%$ of the "after market" segment. The company is placed in Bistrita and it has nine logistics centers: two in Bucharest and by one in Braila, Brasov, Craiova, Deva, Iasi, Oradea and Ramnicu Valcea.

The company will invest this year, 4.2 million euros in expanding production capacity, upgrading the capacity of plastic injection and expansion of facilities to recover lead from batteries. Investments aimed at building an area of 2,700 square meters, and they bought the latest equipment technology from Italy, Great Britain and Sweden.

Given this high volume of production of car batteries, the environmental impact and energy consumption is considerable, including the production stage of the life cycle of this type of product.

This is why it is required using of scientific methods of investigation and evaluation of these effects. The proposed method is Life Cycle Assessment (LCA).

\section{WHY LIFE CYCLE ASSESSMENT ?}

Due to the overall look of the process and product Life Cycle Assessment was considered as an analysis "from birth to death" (Bernardes et al., 2004). Life Cycle Assessment (LCA) is a method by which energy and material consumption are measured on the one hand, and the impact on human health and ecosystems, on the other.

Life cycle phases are considered representative both during significant phases of production process to obtain product and during its using.

This aspect includes the extraction of raw materials, product recycling and its transport to the waste landfill.

Evaluation of a product life cycle is very important because after evaluation of environmental and human health impacts it can occur in order to reduce and even eliminate these impacts.

\section{WORK STAGES}

Life Cycle Assessment involves the following steps (http://www.pre-sustainability.com/content/lca-methodology):

- Establishing of the principal scope of the LCA study;

- Realization of an inventory for input and output system;

- Identifying and assessing potential impacts arising from these inputs and outputs on environment;

- Results interpretation, conclusions, recommendations.

Life Cycle Analysis means required data and information collection (materials, energy and natural resources) during the manufacturing process and their using. The next stage is the components product disassembly and recovery procedures and process analysis and environmental impact identification that appear after disassembly of the product.

For drawing diagrams of a product life cycle it is provided a very detailed database on the characteristics of the elements which influence the life cycle. Life cycle analysis of product can be completed with technical, organizational recommendations in order to mitigate the effects that occur on human health and the environment.

\section{LIFE CYCLE ANALYSIS OF THE PRODUCTION CAR BATTERY 12V 52AH MADE BY SC ROMBAT S.A. BISTRITA USING SIMA PRO 7 SOFTWARE}

The present study is developped on car battery $12 \mathrm{~V} 52 \mathrm{AH}$ made by S.C. ROMBAT S.A. Bistrita

Batteries are made of five main parts (Bernardes et al., 2004) figure 1 :

- a vat of durable plastic;

- lead plates;

- plastic separators walls;

- diluted solution of sulfuric acid and water = electrolyte; 


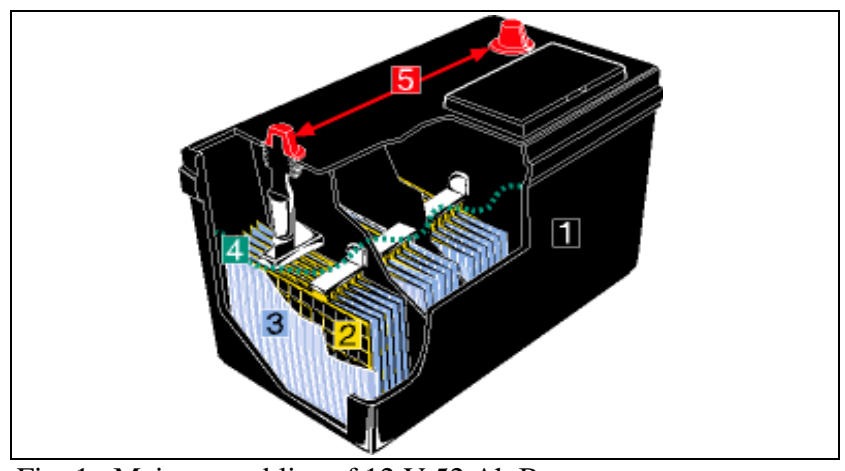

Fig. 1. Main assemblies of $12 \mathrm{~V} 52$ Ah Battery

- lead terminals for conection to the car electrical installation;

The manufacturing process begins with the production of the plastic container and its cover. The most automotive battery containers and their covers are made from polypropylene. For a typical 12-volt car battery, the housing is divided into six sections, or cells. The cover is fitted on and sealed when the battery is finished

(http://www.scribd.com/doc/52217178/internship-report-ofpakistan-accumulaters-pvt-limited-volta-osaka-batteries).

To obtain the components in the "production phase" is necessary to identify materials and specific weight of each part. The components of $12 \mathrm{~V}-55 \mathrm{Ah}$ battery were identified and weighed in the laboratory of "Vasile Alecsandri" University of Bacau. For materials identification of components elements a battery offered by Rombat. S.A., was used.

After the process reconstruction for obtaining of the 13 components of the batteries it will be assembly all components in order to obtain the final product-52Ah $12 \mathrm{~V}$ battery. All components can be observed, for 800 batteries - 12V-52 Ah type, in order of modelling and visualization of environmental impacts. In this report, the energy consumption required to obtain 800 batteries was taken into consideration-figure 2 .

After reconstitution of these batteries through assembling all components it is realized the production tree using EcoIndicator 95.

With this program it is possible to realise the production tree for each component or final product.

For production tree construction, Sima Pro software will take into account all energy consumption required to obtain materials of components, and it will take into account the quantity of needed material to obtain them (Swarr et al., 2011). For complete impacts quantification of the life cycle for the battery $12 \mathrm{~V}-52 \mathrm{Ah}$ it is necessary to configure the end of life of each component, specifying the necessary processes (recycling, re-use, abandonment, incineration or final disposal).These data will be completed for each component.

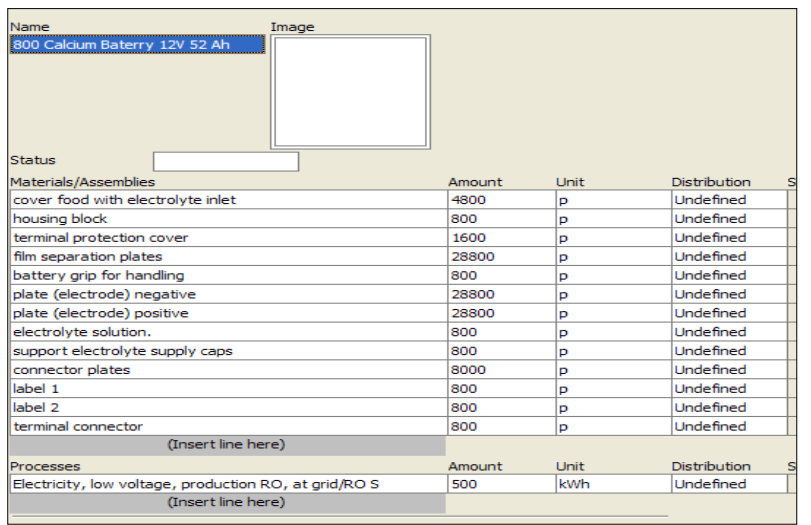

Fig. 2. Pointing out of the needed components for 800 batteries $12 \mathrm{~V}-52$ Ah type

\section{CONCLUSIONS}

According to the obtained results from the modelling of life cycle, the production stage of 800 batteries - $12 \mathrm{~V}-52 \mathrm{Ah}$ type, is the major impact on the environment, compared to other life stages. So, the main significant effect on environmental impact is acidification, a phenomenon resulting from the transformation of sulfur dioxide.

Small positive effects were obtained on the end of life by recycling components. In the recycling process, heavy metals result (Ghenadi et al., 2008).

Unlike currently used methods, which take into account only manufacturing processes harmful effects on the environmental factors, the method proposed in this paper makes a comparative assessment of specific energy consumption.

Recovery and reuse of renewable resources means solving the contradiction between the requirements of the economic growth and the restrictive character of the resources. The immediate challenge is the search of reliable economic methods of environmentally appropriate.

Using LCA method, Rombat S.A. is able to perform some necessary activities such as:

- to identify opportunities to improve the overall environmental aspects of products in different phases of the life cycle of batteries;

- decision making at the factory or the industrial branch, government organizations (eg.: priorities setting, products and processes designing or redesigning).

Production and recycling of batteries assume energy consumption and significant and important environmental impacts. All the details should receive special attention both during constructive design and process design of the battery technology to minimize the possible impact

A general feature of qualitative analysis is how different aspects are compared. Methods of life cycle evaluation are, by definition, comparative. The lack of quantitative analysis prevents comparison of several processes and thus it may reduces the effect of qualitative methods.

\section{ACKNOWLEDGEMENTS}

I want to thank to ROMBAT S.A. for its support given to me in achievement of the study case.

\section{REFERENCES}

Bernardes, A. M.; Espinosa, D. C. R., \& Tenório, J. A. S.(2004), Recycling of batteries: a review of current processes and technologies, Journal of Power Sources, Volume 130, Issues 1-2, 3 May 2004, Pages 291298, ISSN 0378-7753

Ghenadi, A.; Silav, C., \& Obreja C.,(2008), Ciclul de viata al produsului, Editura Alma Mater, Pages 1-158, ISBN-978606-527-001-5, Bacău

Swarr, T. E, et al. (2011), Environmental life-cycle costing: a code of practice, International Journal of Life Cycle Assessment, Vol.16, No 5/June 2011, Pages 389-391, ISSN: 1614-7502 (electronic version)

*** (2010) http://www.scribd.com/doc/52217178/internshipreport-of-pakistan-accumulaters-pvt-limited-volta-osakabatteries, COMSATS Institute of InformationTechnology, Sahiwal, Accessed on: 2011-02-21

*** (2010) http://www.pre-sustainability.com/content/lcamethodology, LCA Methodology-Introduction to LCA with SimaPro 7, Accessed on: 2011-01-11 